\title{
Primary sclerosing cholangitis
}

INSERM

\section{Source}

INSERM. (1999). Orphanet: an online rare disease and orphan drug data base. Primary sclerosing cholangitis. ORPHA:171

Primary sclerosing cholangitis (PSC) is a rare, slowly progressive liver disease characterized by inflammation and destruction of the intra- and/or extra-hepatic bile ducts that lead to cholestasis, liver fibrosis, liver cirrhosis and ultimately liver failure. 